\title{
ADRENAL CEVERNOUS HEMANGIOMA
}

M. Ivović, Lj. Marina, S.Vujović, M. Tančić-Gajić, A. Diklić.

UNIVERSITY OF BELGRADE

SCHOOLOF

MEDICINE

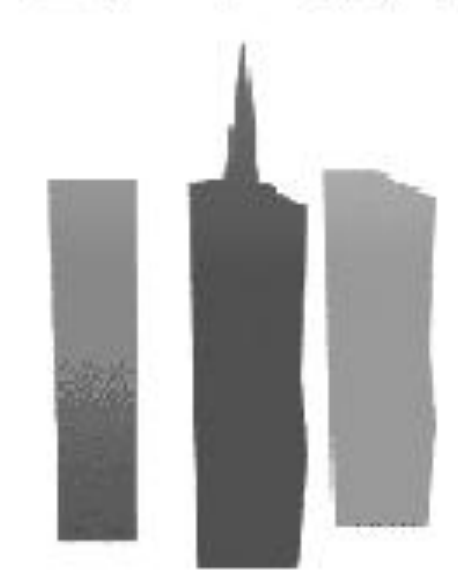

Z. Arizanović, D. Micić

Clinic for Endocrinology,

diabetes and metabolic disease, Clinical Center Serbia

School of Medicine

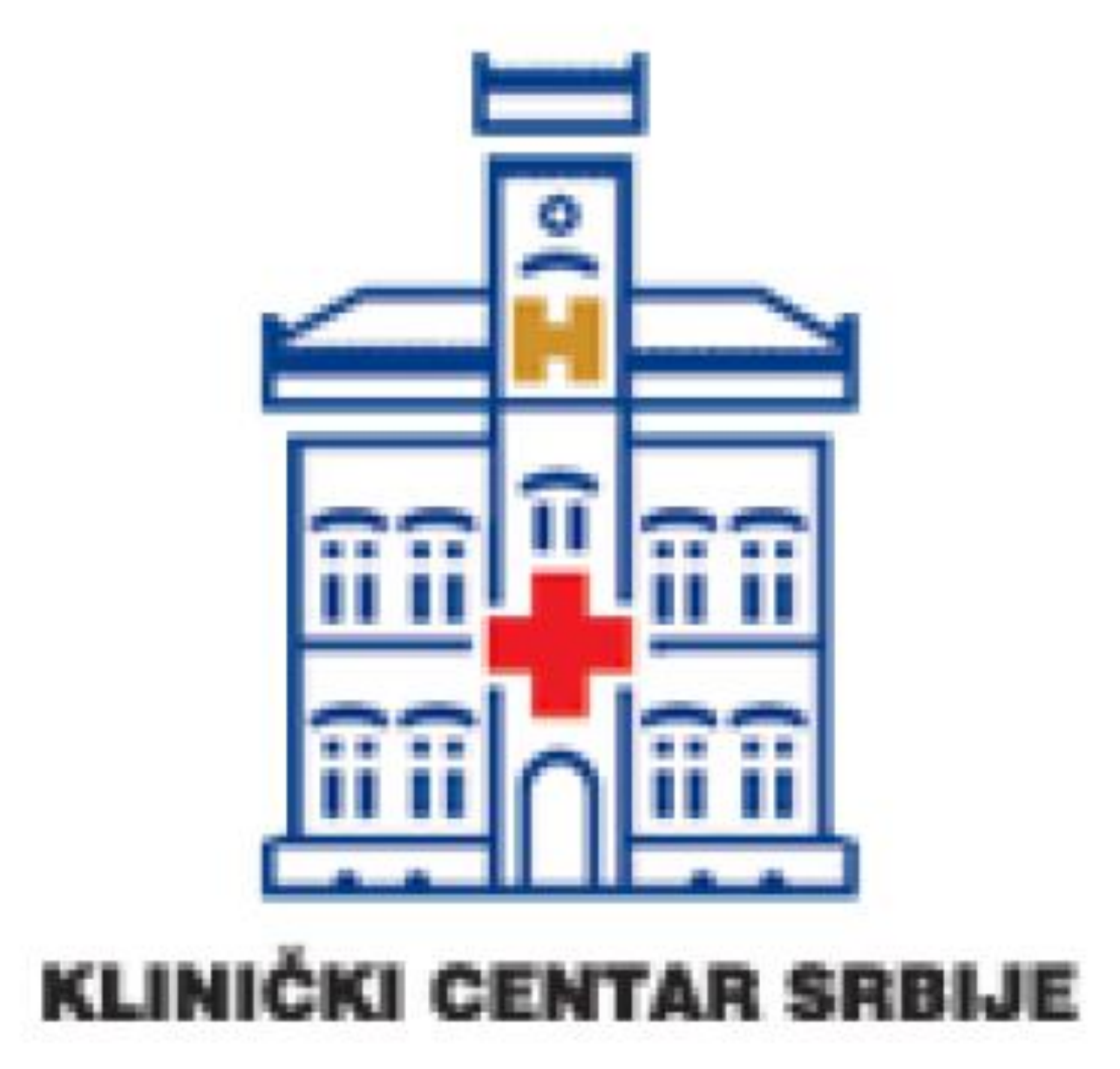

\section{Introduction:}

Adrenal hemangioma is a rare adrenal tumor usually presented as incidental finding in asymptomatic patients. Due to its radiographic features sometimes it's difficult to differentiate them from other malignant lesions.

\section{Case report:}

We present a 55 years old men admitted to our department with adrenal incidentaloma size $5 \times 4 \mathrm{~cm}$ confirmed by MSCT scan. Active pheochromocythoma was excluded by normal urinary catecholamines. Endocrine evaluations revealed normal midnight cortisol, with post $1 \mathrm{mg}$-DST cortisol suppression and normal basal ACTH. PRA and Aldosteron were in normal range with normal ALD/PRA ratio. According to MSCT tumor had some malignant neoplastic features. Surgery was performed. Intraoperative findings showed adrenal tumor about $5 \mathrm{~cm}$ sizes without signs of local infiltration or lymphadenopathy. Tumor was completely removed with adrenalectomy.

Pathohistology showed cavernous and partially capillary hemangioma with hyperplasia of the rest of adrenal gland.
6 months later he was retested and results show normal function of the left adrenal gland.

\section{Conclusion:}

Most of adrenal cavernous hemangioma was non-functional and surgical removal was the write choose of therapy.

They should be also the part of differential diagnosis of adrenal incidentaloma.

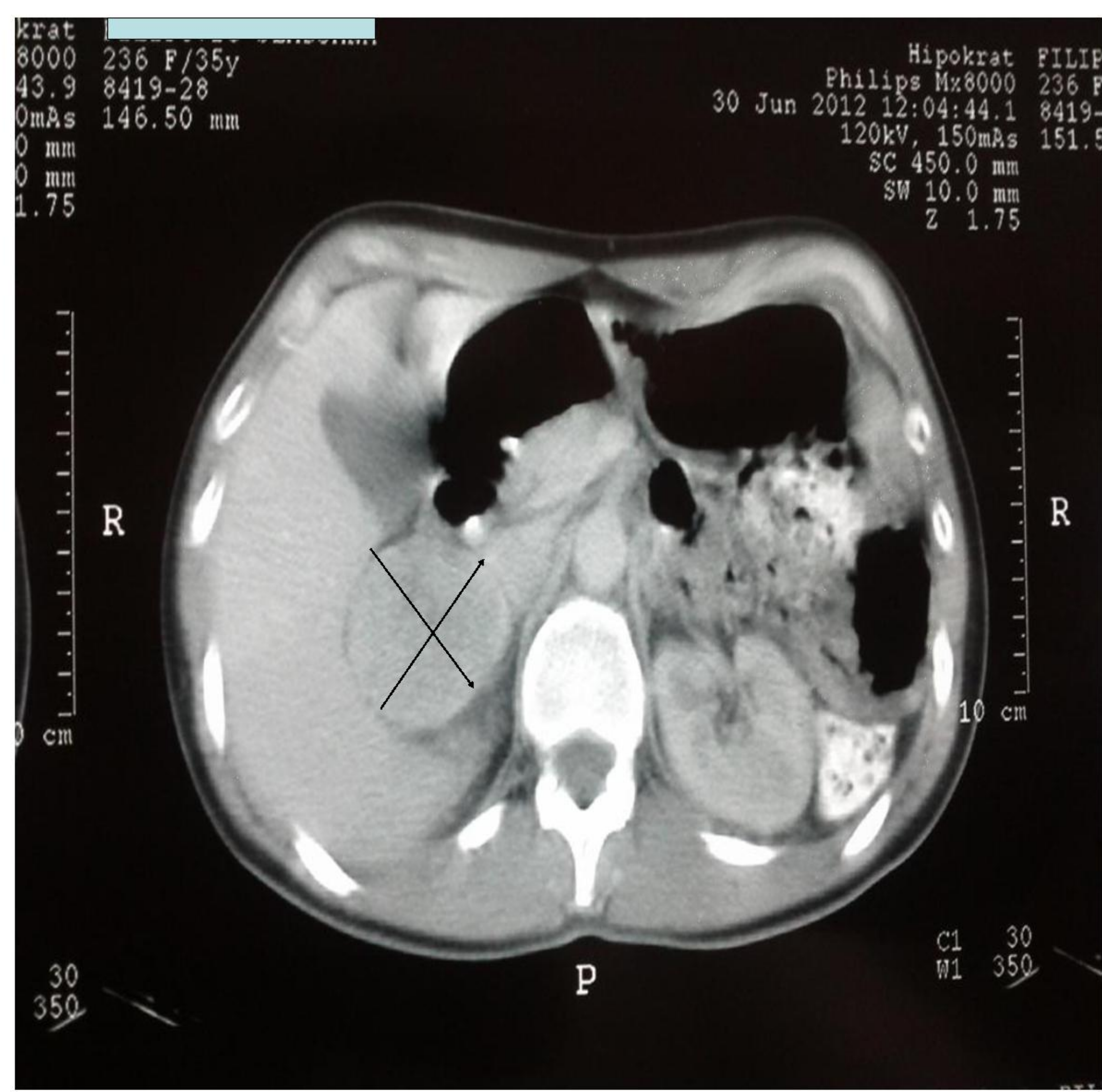

